\title{
Effect of oat gum on the physical properties of the gastrointestinal contents and on the uptake of $D$-galactose and cholesterol by rat small intestine in vitro
}

\author{
BY E. K. LUND, J. M. GEE, J. C. BROWN, P. J. WOOD* AND I. T. JOHNSON† \\ AFRC Institute of Food Research, Norwich Laboratory, Colney Lane, Norwich NR4 7UA
}

(Received 12 July 1988 - Accepted 1 February 1989)

\begin{abstract}
Recent reports indicate that oats have a relatively low glycaemic effect in comparison with other carbohydrate food, and that their consumption leads to a reduction in plasma-cholesterol levels in man. These properties may be due to a soluble non-starch polysaccharide in oats. The present study was undertaken to explore the physiological properties of this material. Three groups of male Wistar rats were meal-fed on a control diet free of soluble dietary fibre for $10 \mathrm{~d}$ before being given a $10 \mathrm{~g}$ meal of either the control diet, a diet containing oat gum ( $\beta$-glucan), or finely ground rolled oats. The contents of the stomach, small intestine and caecum were later recovered and the weight, water content and viscosity were measured. The small intestinal contents from oat-gum-fed or oat-fed rats had a higher wet: dry weight ratio than that of the controls, and a higher viscosity. In in vitro studies the rate of uptake of D-galactose by jejunal rings was reduced in the presence of oat gum. The estimated Michaelis-Menten constant for the carrier-mediated component in the presence of oat gum was higher than that for controls, but the maximum transport rates were similar. Cholesterol uptake by everted jejunal sacs was progressively inhibited by increasing concentrations of oat gum in the mucosal medium. It is concluded that increased viscosity of the contents of the small intestine may contribute to the low glycaemic index and hypocholesterolaemic effects of oats in man. Oats appear to be amongst the few palatable sources of viscous dietary fibre in the conventional Western diet.
\end{abstract}

Cholesterol: Dietary fibre: Oats: Rat

It is now widely recognized that the various polysaccharides which comprise dietary fibre differ considerably in their biological effects. There is particular interest at present in the soluble non-starch polysaccharides that are known to influence carbohydrate and lipid metabolism in man, and can be used in the management of diabetes mellitus and some forms of hyperlipidaemia. The precise mechanism of action of materials such as guar gum and pectin is not completely understood, but there is evidence that the viscosity they impart to the chyme, after dispersion in the small intestinal lumen, increases transit time and reduces the rate of nutrient absorption (Jenkins et al. 1978; Blackburn et al. 1984).

Despite the effectiveness of even relatively small quantities of isolated polysaccharides given as supplements to the diet under experimental conditions, their relative unpalatability has limited their clinical use. Attention has, therefore, been focused on the possibility of modifying the diet to provide an enriched intake of soluble dietary fibre from whole food. Significant improvements in diabetic controls have been reported by groups using diets high in legumes (Simpson et al. 1981). There are few items in traditional Western diets which can provide viscous polysaccharides in significant quantities. Oats are unusual, however, in that the bran fraction contains substantial quantities of $(1 \rightarrow 3)(1 \rightarrow 4)$ - $\beta$-Dglucan, an unbranched, soluble polysaccharide with a high viscosity in water (Wood, 1986).

* Present address: Agriculture Canada, Food Research Centre, Ottawa, Ontario K1A OC6, Canada.

$\dagger$ For reprints. 
Table 1. Composition of diets $(\mathrm{g} / \mathrm{kg})$

\begin{tabular}{|c|c|c|c|}
\hline Diet... & Control & Oat gum & Rolled oats \\
\hline Starch & 290 & 290 & - \\
\hline Sucrose & 290 & 290 & - \\
\hline Casein & 200 & 200 & - \\
\hline Maize oil & 80 & 80 & - \\
\hline Cellulose* & 80 & 40 & - \\
\hline Mineral mix $\dagger$ & 40 & 40 & - \\
\hline Vitamin mix $\ddagger$ & 20 & 20 & - \\
\hline Oat gum & - & 40 & - \\
\hline Ground oats & - & - & 10008 \\
\hline
\end{tabular}

* Solkaftoc; Johnson, Jorgensen, Wettre Ltd, London.

$\dagger$ Minerals (g/kg diet): $\mathrm{CaHPO}_{4} 13 \cdot 00, \mathrm{CaCO}_{3} 8 \cdot 20, \mathrm{KCl} 7 \cdot 03, \mathrm{Na}_{2} \mathrm{HPO}_{4} 7 \cdot 40, \mathrm{MgSO}_{4} \cdot \mathrm{H}_{2} \mathrm{O} 4 \cdot 00, \mathrm{MnSO}_{4} \cdot \mathrm{H}_{2} \mathrm{O}$ $0 \cdot 18, \mathrm{ZnCO}_{3} 0 \cdot 10, \mathrm{FeSO}_{4} \cdot 7 \mathrm{H}_{2} \mathrm{O} 0 \cdot 144, \mathrm{CuSO}_{4} .5 \mathrm{H}_{2} \mathrm{O} 0 \cdot 023, \mathrm{KIO}_{3} 0.001$

$\$$ Vitamin mix $(\mathrm{mg} / \mathrm{kg}$ diet): nicotinic acid 60 , cyanocobalamin in mannitol 50 , calcium D-pantothenate 40 , thiamin hydrochloride 10 , riboflavin 10 , pteroylmonoglutamic acid 10 , D-biotin 1, vitamin $\mathrm{K}_{1}$, pyridoxine 10 , Rovimix E-50 150, Rovimix A-500 25, Rovimix $\mathrm{D}_{3}-50015$, choline bitartrate 1800.

$\S$ Oats contain approximately $40 \mathrm{~g}$ oat gum $/ \mathrm{kg}$ which is equivalent to $3.2 \mathrm{~g} \beta$-glucans $/ \mathrm{kg}$.

The purpose of the present study was to investigate the effect of isolated oat gum on the rheological properties of the gastrointestinal contents, and on the transport of nutrients in vitro.

\section{MATERIALS AND METHODS \\ Animals}

Male Wistar rats $(200-300 \mathrm{~g})$ were obtained from a commercial supplier and fed on a standard pellet diet before being transferred to the experimental diets described later. The animals were killed by injection of sodium pentobarbital (Euthetal; May and Baker Ltd, Dagenham) at a dose of $150 \mathrm{mg} / \mathrm{kg}$ body-weight, followed by cervical dislocation.

\section{Diets}

The compositions of the control and experimental semi-synthetic diets are given in Table 1. Oat gum was prepared at the POS Pilot Plant, Saskatoon, Canada, by alkaline extraction similar to the method of Wood et al. (1978), and contained approximately $800 \mathrm{~g} \beta$ glucans $/ \mathrm{kg}$ gum. Food-quality rolled oats were purchased locally and finely ground. Guar gum was purchased from Sigma (Poole, Dorset) in the form of finely ground flour.

\section{Radiochemicals}

D- $\left[1-{ }^{3} \mathrm{H}\right]$ galactose, $\left[{ }^{14} \mathrm{C}\right]$ polyethylene glycol 4000 (molecular weight 4000 ) and $\left[1 \alpha 2 \alpha(n)-{ }^{3} \mathrm{H}\right]$ cholesterol were obtained from Amersham International plc, Amersham, Bucks.

\section{Feeding study}

Thirty-six rats were trained to eat $10 \mathrm{~g}$ control diet between 09.00 and 10.00 hours each day for a period of $10 \mathrm{~d}$. On the final day of the study, rats were given $10 \mathrm{~g}$ of either the control diet, the gum-supplemented diet, or $10 \mathrm{~g}$ ground oats, $6-7 \mathrm{~h}$ before being killed. The mean weight of the rats and the average time of killing after being fed were the same for each group. Immediately after cervical dislocation, the abdomen was opened by a mid-line incision and the stomach, small intestine, colon and caecum removed. The $\mathrm{pH}$ of the caecal 
contents was determined by direct insertion of a semi-micro $\mathrm{pH}$ electrode. Each organ was opened fully, and the contents collected, by gentle scraping, and immediately weighed. The wet: dry weight ratio of a subsample was determined by drying at $85^{\circ}$ for $18 \mathrm{~h}$ in a fan oven. Where possible, the viscosities of the gastrointestinal contents were determined directly using a rotary viscometer with cone and plate attachment (Epprecht Rheomat 15; Contraves AG, Zurich, Switzerland) at a shear rate of $50 / \mathrm{s}$ and temperature of $37^{\circ}$. The contents were then centrifuged for $5 \mathrm{~min}$ in a high-speed bench centrifuge (model no. 5414; Ependorf, Hamburg, West Germany), the supernatant fraction was collected and the viscosity measured again.

\section{Unstirred-layer measurements}

In order to prepare oat-gum solutions of equivalent viscosity to the intestinal contents for use in vitro, a series of solutions was made by gradually adding the gum to either distilled water or Krebs-bicarbonate buffer at $37^{\circ}$, using a high-speed vortex homogenizer (UltraTurrax; Janke and Kunkel KG, West Germany). The suspension was left for $1.5 \mathrm{~h}$ at $37^{\circ}$ and briefly homogenized before use. The final suspensions were uniform translucent liquids. The viscosities, measured as described previously, remained consistent for at least $3 \mathrm{~h}$, and were similar in both aqueous systems. A range of concentrations of guar gum in Krebs-Ringer buffer was similarly prepared for comparison, and allowed to stand at $37^{\circ}$ for $2 \mathrm{~h}$, by which time such solutions attain approximately $95 \%$ of their final viscosity (J. M. Gee, unpublished results).

Estimates of the thickness of the unstirred layer in the presence and absence of $8.5 \mathrm{~g}$ oat gum $/ 1$ were made as described previously by Johnson \& Gee (1981), using a technique based on that of Diamond (1966). Everted jejunal segments approximately $50 \mathrm{~mm}$ in length were ligatured at one end, tied over glass cannulas, filled with Krebs-bicarbonate buffer and suspended in tubes containing pre-gassed (oxygen-carbon dioxide, 95:5 v/v) Krebsbicarbonate buffer and glucose $(28 \mathrm{~mm})$, with or without $8.5 \mathrm{~g}$ oat gum $/ 1$ at $37^{\circ}$. During the 15 min pre-incubation period, tubes were gassed continuously; gassing was subsequently stopped during measurement of glucose transfer potential. The transmural potential was monitored by potassium chloride-agar bridges led via calomel half-cells to a modified Keithley digital multimeter 177 (Keithley, Reading, Berks) with a chart recorder attached. Once a steady potential difference (PD) had been achieved, sacs were transferred to Krebs buffer-glucose solution $(28 \mathrm{~mm})$, with or without oat gum as described previously, containing mannitol $(100 \mathrm{mM})$, and the time-interval taken to achieve a new steady osmotically-induced PD was used to calculate the thickness of the effective unstirred water layer using the formula:

$$
S=\left(\frac{D \times t}{0.38}\right)^{\frac{1}{2}} \times 10^{4}
$$

where $S$ is the thickness of the layer $(\mu \mathrm{m}), t$ is the half time (s) and $D$ is the diffusion coefficient for mannitol in water at $37^{\circ}\left(9 \cdot 29 \times 10^{-6} \mathrm{~cm}^{2} / \mathrm{s}\right.$; Pollay et al. 1969).

Alternatively, sacs pre-incubated in oat gum were transferred to Krebs buffer-glucose solution, allowed to establish a steady PD and then transferred to Krebs buffer-glucose solution and mannitol (100 mM).

In further experiments gassing was continuous throughout the recording of PD changes at a rate consistent with the maintenance of a steady reading on the chart recorder (about 1 bubble/s) with the gas tube away from the agar bridge.

\section{Uptake measurements}

For the measurement of galactose uptake kinetics, rats which had been fed on the commercial pellet diet ad lib. were killed and the small intestine was removed, rinsed and 
everted. The most proximal $10 \%$ was discarded and the next $40 \%$ of the total length cut into 2-3 $\mathrm{mm}$ rings. Galactose uptake was measured by incubating three to five rings from each animal in Krebs-bicarbonate buffer containing 5, 10, 20, 40 or $60 \mathrm{mM}$-D-galactose labelled with $\mathrm{D}-\left[{ }^{3} \mathrm{H}\right]$ galactose $(1 \mu \mathrm{Ci} / \mathrm{ml})$, in the presence or absence of oat gum $(8 \cdot 5 \mathrm{~g} / \mathrm{l})$. The solution had a viscosity of $100 \mathrm{mPa} / \mathrm{s}$, and contained approximately $6.8 \mathrm{~g} \beta$-glucan $/ 1$. The osmolarity of all incubation solutions was maintained by replacing D-galactose by mannitol to give a final osmolarity of $324 \mathrm{mosmol} / 1$. Incubations were carried out in a vigorously shaking water bath (120 oscillations/min) with continuous gassing $\left(\mathrm{O}_{2}-\mathrm{CO}_{2}\right.$, $95: 5 \mathrm{v} / \mathrm{v}$ ) at $37^{\circ}$ for $4 \mathrm{~min}$, after which transport was stopped by draining the incubation mixture through a Buchner funnel and washing the rings with $75 \mathrm{ml}$ ice cold saline $(9 \mathrm{~g}$ sodium chloride/1). After rinsing, all tissue samples were placed in glass vials and dried overnight at $85^{\circ}$. The dried residues were dissolved in concentrated nitric acid $(0.4 \mathrm{ml})$ and mixed with $0.75 \mathrm{M}$-Trizma base $(3.6 \mathrm{ml})$. Portions of the solution $(0.5 \mathrm{ml})$ were diluted to $2 \mathrm{ml}$ with distilled water, added to $18 \mathrm{ml}$ scintillation fluid (Cocktail T, Scintran; BDH, Poole, Dorset) and counted on a Philips PW 4700 liquid-scintillation spectrometer. The passive uptake of the sugar for each rat was found by adding phloridzin (phloretin-2- $\beta$-Dglucoside; Sigma) at a concentration of $0.5 \mathrm{mmol} / 1$ to the previously described incubation media. The uptake under these conditions was then subtracted from the total transport to give the carrier-mediated uptake.

For the measurement of cholesterol uptake, a suspension of micelles was prepared in calcium-free Krebs-bicarbonate buffer containing $10 \mathrm{~mm}$-glucose. The suspension contained sodium taurocholate $(5 \mathrm{~mm})$, monolein $(0.3 \mathrm{~mm})$, oleic acid $(0.6 \mathrm{~mm})$ and cholesterol $(0 \cdot 1 \mathrm{~mm})$ together with $\left[{ }^{3} \mathrm{H}\right] \mathrm{cholesterol}(0 \cdot 1 \mu \mathrm{Ci} / \mathrm{ml})$. This was sonicated to give a clear suspension to which $\left[{ }^{14} \mathrm{C}\right]$ polyethylene glycol $4000(0.025 \mu \mathrm{Ci} / \mathrm{ml})$ was added as an extracellular marker (Chow \& Hollander, 1978).

Eight everted sacs approximately $30 \mathrm{~mm}$ in length were prepared from the proximal jejunum. Each sac was placed in a $25 \mathrm{ml}$ conical flask containing $5 \mathrm{ml}$ of the previously described medium. The control flask was free of oat gum; the remaining seven flasks contained $1,2,4,6,8$ or $10 \mathrm{~g}$ oat gum $/ 1$ of medium. The flasks were incubated for $10 \mathrm{~min}$ in a vigorously shaking water bath with continous gassing. Tissue samples were treated as described previously.

\section{Statistics}

The significance of differences between means was determined using unpaired $t$ tests. To estimate the kinetic variables of carrier-mediated galactose transport, the MichaelisMenten model was fitted to the values using the non-linear regression method of Duggleby (1981) which provides standard errors for the estimated values.

\section{RESULTS}

Visual inspection of the gastrointestinal contents revealed obvious differences in their physical characteristics and the quantities recovered from the three groups of rats. The meal-feeding regimen ensured that a substantial proportion of the test meals remained in the stomach and small intestines at the time of death (Fig. 1). The stomach contents of all the groups were pastes rather than liquids, but those of the animals given oat or oat gum appeared harder and drier than those of the controls. This pattern was reversed for the small intestinal chyme, however. Whilst in the controls the recovered material was again paste-like, in both the treatment groups it was liquid in form with a creamy or syrupy texture and had a considerably greater total bulk as a result of its high water content (Fig. 1). The viscosity of this material was close to $2000 \mathrm{mPa} / \mathrm{s}$ in both treatment groups (Table 2). 

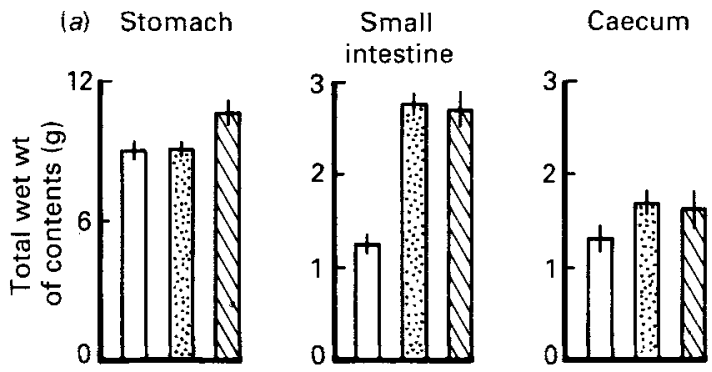

(b)
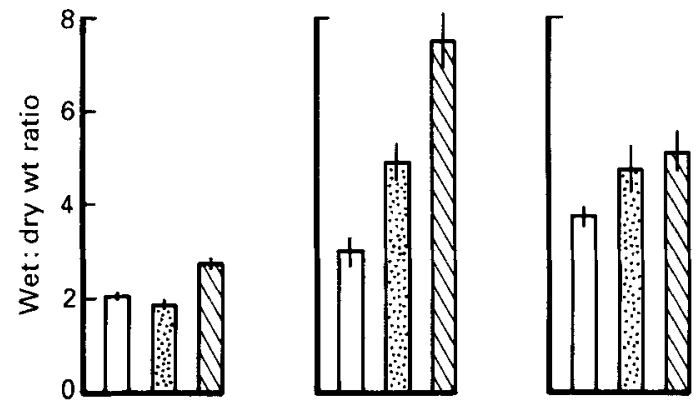

Fig. 1. (a) The total wet weight of the contents of the stomach, small intestine and caecum and $(b)$ the relative wet :dry weight ratio of these contents in adult rats fed on $10 \mathrm{~g}$ control $(\square)$, oat gum $(\square)$ and ground oat $(\mathbb{Q})$ diets 6.6 (SE $0 \cdot 7$ ) h previously. Values are means with their standard errors represented by vertical bars. For details of diets see Table 1 .

Table 2. Viscosity of the small intestinal contents of rats fed on a control diet, oat-gumsupplemented diet or ground oats

(Values are means with their standard errors for the no. of determinations shown in parentheses)

\begin{tabular}{|c|c|c|c|c|}
\hline \multirow[b]{3}{*}{ Diet* } & \multicolumn{4}{|c|}{ Viscosity $(\mathrm{mPa} / \mathrm{s})$} \\
\hline & \multicolumn{2}{|c|}{ Total contents } & \multicolumn{2}{|c|}{ Supernatant fraction } \\
\hline & Mean & $\mathrm{SE}$ & Mean & $\mathrm{SE}$ \\
\hline Control & NM & - & $<2$ & - \\
\hline Oat gum & 1877 & $252(12)$ & 111 & $-(1)$ \\
\hline Ground oats & 1868 & $184(12)$ & 820 & $28(4)$ \\
\hline
\end{tabular}

NM, not measurable.

* For details, see Table 1.

Although the viscosity of the whole chyme from the control animals was unmeasurable, a liquid supernatant fraction was obtained after centrifugation; the viscosity of this fraction was not measurably different from that of water. It proved more difficult to separate a distinct supernatant fraction from the lumen contents of the treatment groups, but small volumes were obtained from each animal and, when pooled, these had measurable viscosities much higher than that of water, indicating the presence of hydrated polymer (Table 2).

The total bulk of material in the caeca of the treatment groups was higher than that of 


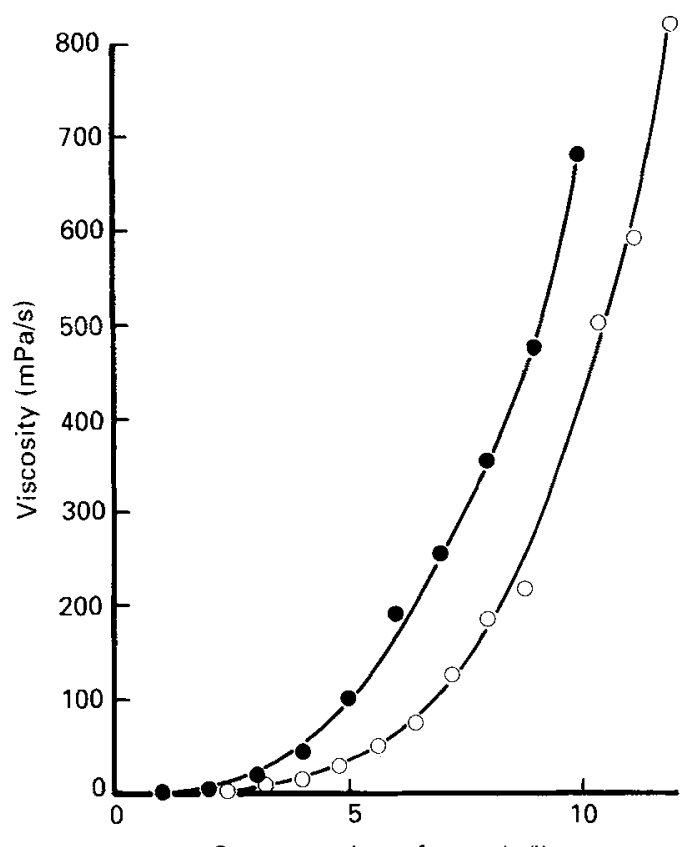

Concentration of gum $(\mathrm{g} / \mathrm{l})$

Fig. 2. The viscosity of oat gum $(O)$ and guar gum (O). For oat gum, the concentration of $\beta$-glucans is plotted rather than that of the crude gum. For details of procedures, see p. 93.

Table 3. Effect of oat gum on the resistance to diffusion of the jejunal unstirred water layer $(U W L)$ in vitro

(Values are means with standard errors for the no. of determinations shown in parentheses)

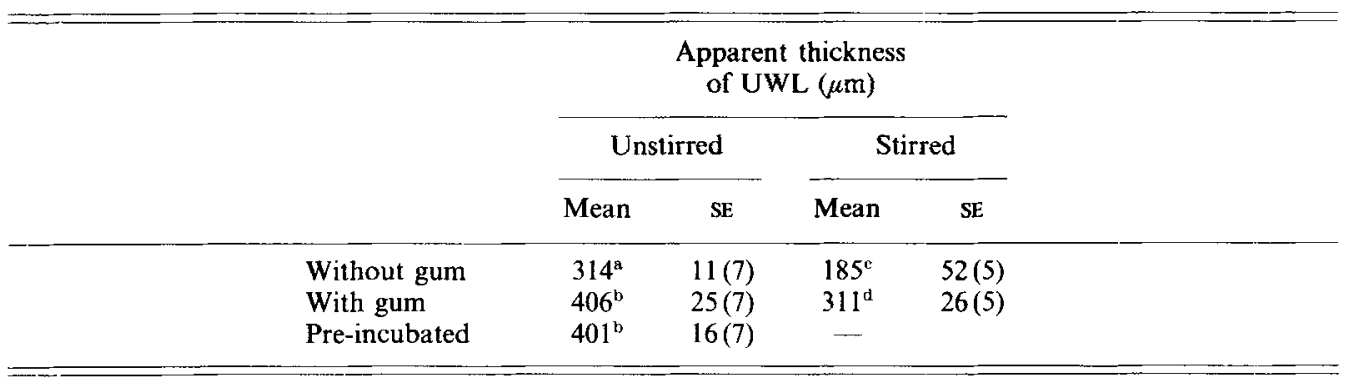

${ }^{a-d}$ Mean values with different superscript letters differed significantly $(P<0.05)$.

the controls, but its texture was again paste-like in all the groups. The mean pH values of the caecal contents in the oat-gum-fed and whole-oat-fed groups were 6.95 (SE 0.04) and 6.72 (SE 0.06) respectively, compared with 7.15 (SE 0.06) in the control group. Both the treatment values were significantly lower than those of the controls $(P<0.05)$.

Aqueous suspensions of isolated oat gum were prepared so as to simulate the intralumen conditions of oat-fed rats, and were used for transport studies in vitro. The relation between concentration and viscosity for isolated oat gum is shown in Fig. 2, and a comparison with guar gum is also included. The effect of an oat gum suspension with a viscosity of $100 \mathrm{mPa} / \mathrm{s}(8.5 \mathrm{~g} / \mathrm{l})$ on the apparent thickness of the mucosal unstirred water layer in isolated rat jejunum is shown in Table 3 . When the isolated sacs were placed 


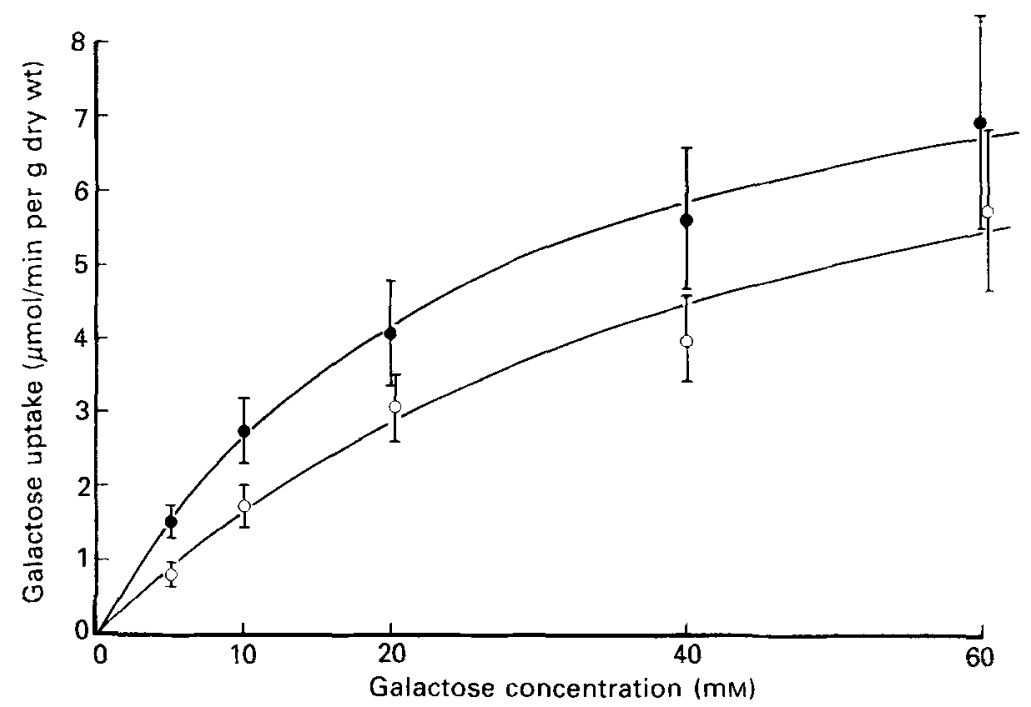

Fig. 3. The sodium-dependent uptake of D-galactose by small intestinal rings in the presence (O) and absence (O) of oat gum $(8.5 \mathrm{~g} / \mathrm{l})$, in Krebs-bicarbonate buffer, containing different concentrations of D-galactose, Values are means with their standard errors represented by vertical bars. Mean values were significantly different at 5,10 and $40 \mathrm{~mm}(P<0.05)$. Curves were derived from the Michaelis-Menten equation using the kinetic variables described on p. 98 . For details of procedures, see p. 94.

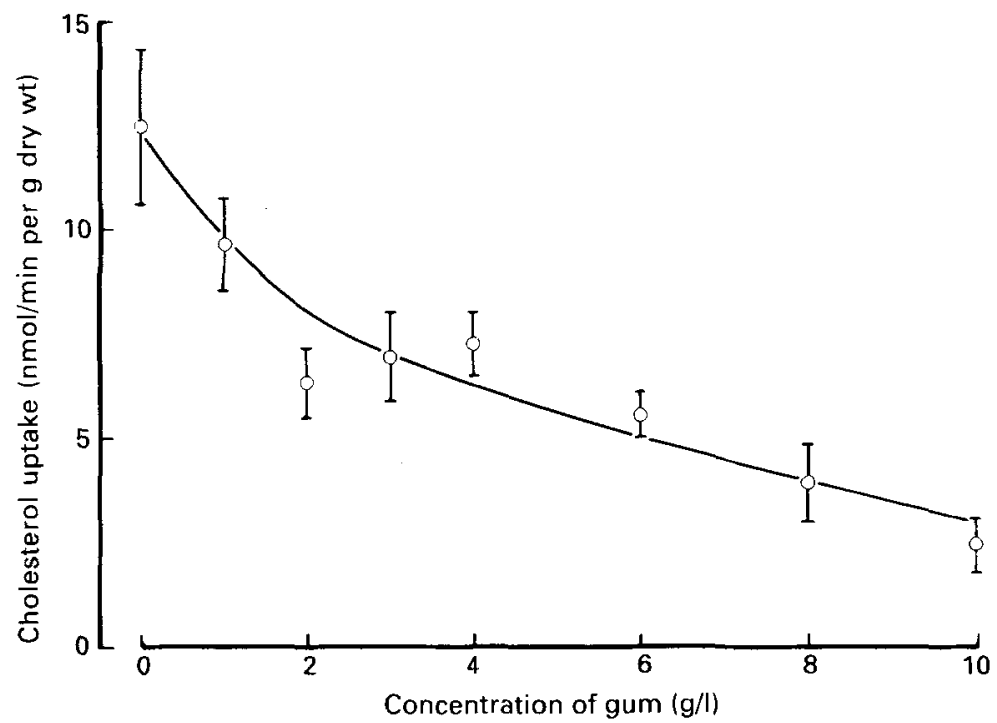

Fig. 4. The uptake of cholesterol by everted sacs of jejunum, incubated for $10 \mathrm{~min}$ in Krebs-bicarbonate buffer containing labelled micelles and a range of concentrations of oat gum. Values are means with their standard errors represented by vertical bars. For details of procedures, see p. 94.

directly into, or pre-incubated in the oat gum, the effect was to increase the apparent thickness of the layer by over $20 \%$ compared with sacs incubated in a gum-free medium. When stirring was continued during measurement of transmural potential, the apparent thickness of the unstirred layer was reduced in both control and test sacs, but a significantly higher value was still observed in the presence of the oat gum. 
The rate of galactose uptake by isolated rings of rat jejunum was reduced by oat gum over the whole range of galactose concentrations studied, although the reduction was proportionately greater at lower concentrations (Fig. 3). Analysis of the kinetic values indicated that this was not due to any significant decrease in the maximum transport rate $\left(J_{\max }\right)$ in the presence of oat gum $(9.9$ (SE $2 \cdot 2) \mu \mathrm{mol} / \mathrm{min}$ per g dry weight) compared with the gum-free control $(9.6$ (SE 0.5$) \mu \mathrm{mol} / \mathrm{min}$ per g dry weight), but the estimated MichaelisMenten constant (50.1 (SE 15.6) $\mathrm{mM}$ ) in the presence of oat gum was almost double that of the control (26.2 (SE 2.2) $\mathrm{mM})$.

The rate of uptake of cholesterol by everted sacs was reduced by the presence of oat gum in the incubation medium (Fig. 4). As the concentration of oat gum was increased there was a non-linear reduction in uptake. Sacs incubated in $3 \mathrm{~g}$ oat gum $/ 1$ absorbed $55 \%$ of the cholesterol taken up by the control sacs. However, an increase in concentration to $10 \mathrm{~g} / 1$ resulted in a further reduction in transport of only about $35 \%$.

\section{DISCUSSION}

An early clinical study by Jenkins et al. (1978) indicated that amongst several forms of nonstarch polysaccharides which they administered to human subjects in combination with glucose test-meals, only those with a high viscosity led to a significant reduction in postprandial glycaemia. Subsequent investigations by ourselves and others have confirmed that viscous polysaccharides can reduce the rate of glucose absorption in physiological preparations of animal intestine (Johnson \& Gee, 1981; Blackburn \& Johnson, 1981; Rainbird et al. 1984) and in man (Blackburn et al. 1984). The reduction in transport is accompanied by significant changes in the transit of chyme through the small intestine (Brown et al. 1988), but the effect appears to be due primarily to the formation of a poorly stirred boundary layer at the mucosal surface (Johnson \& Gee, 1981 ; Edwards et al. 1988). Attempts to exploit the physiological effects of viscous polysaccharides have led to the development and marketing of pharmaceutical preparations containing guar gum, and to the formulation of cereal products incorporating this material (Apling \& Ellis, 1982). The present study suggests that the $\beta$-glucan fraction of porridge oats may provide an important alternative source of such viscous polysaccharides in the diet.

The addition of oat gum to the diet of rats increased the volume and modified the properties of the small intestinal chyme, changing it from a moist paste to a liquid dispersion with measurable viscosity. Furthermore, the increased viscosity was shown to be associated with the supernatant fraction separated from the whole chyme. This confirmed the presence of dissolved polysaccharide in the aqueous layer bathing the mucosal surface. A similar increase in viscosity has been previously observed in animals fed on semisynthetic diets containing guar gum, but no such enhancement of viscosity occurs in rats fed on a conventional pellet diet (Blackburn \& Johnson, 1981; Horn et al. 1986). Trout et al. (1983) measured the distribution of water and solids throughout the small intestines of animals fed on a diet containing xanthan gum, and also observed a high moisture content. The effect is probably due to enhanced resistance to diffusion of the mucosal unstirred fluid layer associated with the presence of the viscous polysaccharide. This has been shown to reduce the rate of fluid re-absorption in the small intestine of animals (Blackburn \& Johnson, 1983; Rainbird et al. 1984), and man (Blackburn et al. 1984). Such an effect would be expected to favour increased intralumen fluid volume.

The results of the present study confirm that oat gum behaves similarly to other viscous non-starch polysaccharides when eaten as a component of a powdered, semi-synthetic diet. More importantly perhaps, the results also indicate that consumption of a similar quantity of oat gum in the form of whole rolled oats modifies the gut contents in the same way. 
Indeed, the chyme recovered from oat-fed rats had the highest water content of the three groups studied, and yielded the most viscous supernatant fraction after centrifugation.

The effect of oat gum on the rate of nutrient absorption was investigated in vitro, using gum-containing physiological media at a viscosity well within the range observed in the feeding trial. The effect of oat gum on the time-course of osmotically induced PD transients in isolated jejunum indicated that the resistance to diffusion of the aqueous boundary layer was significantly increased, both in stationary media, and under gently stirred conditions, the latter reflecting a more physiological state. According to the theoretical treatment of Thomson \& Dietschy (1977), such an increase in resistance is effectively equivalent to an increase in the thickness of an idealized unstirred water layer overlying the mucosa. It is well recognized that the presence of such layers modifies the kinetics of membrane transport systems so as to cause an apparent increase in the kinetic variable $K_{\mathrm{m}}$, with no change in the maximum transport rate. The kinetic analysis of Fig. 3 confirms that such a rightward shift in the saturable curve describing the active component of galactose transport did occur when the tissue was incubated in the presence of oat gum.

Unlike the actively transported sugars, cholesterol is taken up from micelles by diffusion in the small intestine, and therefore displays linear transport kinetics (Gee et al. 1983). As Fig. 4 illustrates, the absorption of cholesterol by everted sacs of intestine was significantly reduced in the presence of oat gum, even at low concentrations, and continued to fall, though less steeply, as the concentration was increased. The progressive decline in cholesterol uptake may indicate a sieving effect of dispersed $\beta$-glucan polymer on the micelles, which have relatively high molecular volume (Phillips, 1986).

The influence of oat gum on the physical properties of the small intestinal contents may at least partially account for the effectiveness of oats in the management of metabolic disease. The blood glucose response to oats has been investigated by Jenkins et al. (1982), and more recently by Heaton et al. (1988), who have shown that the glycaemic response to cooked oats in healthy subjects is substantially lower than that for wheat products or rice. Simulated digestion studies provide no evidence that cooked porridge oats are digested particularly slowly (Gee \& Johnson, 1985); a more likely explanation for the low glycaemic response is that the absorption of the carbohydrate constituents of oats is delayed by a high intralumen viscosity as has been suggested recently by Heaton et al. (1988). The present study provides firm evidence for this hypothesis. Porridge can perhaps be seen as analogous to manufactured products such as guar bread (Apling \& Ellis, 1982).

Well before the beneficial effects of oats on blood glucose levels had aroused interest, oat products had been reported to exert a negative influence on plasma cholesterol levels in man (De Groot et al. 1963). Later, Judd \& Truswell (1981) observed an $8 \%$ decline in total plasma cholesterol in ten healthy subjects given $125 \mathrm{~g}$ rolled oats daily for 3 weeks, although the effect did not quite reach statistical significance. Subsequent reports by other workers have broadly confirmed these findings (Storch et al. 1984; Van Horn et al. 1986; Gold \& Davidson, 1988). The mechanism by which oat products reduce plasma cholesterol levels is not known. One possibility is that the presence of oat products in the small intestine slows the rate of cholesterol absorption, thus reducing its overall availability from the diet, and increasing faecal excretion (Judd \& Truswell, 1981). The present results provide some evidence for such a mechanism. Another possibility is that the efficiency of the enterohepatic circulation of bile salts is reduced by oat gum. The unstirred layer effect, coupled with a high volume of fluid in the distal ileum, could perhaps slow the rate of bile salt recovery during the digestion of a meal, thereby reducing the effective pool of bile salts, and inhibiting the formation of micelles in the proximal small intestine.

An alternative explanation for the hypocholesterolaemic effect of oat fibre is that the fermentation products of oat gum may exert an inhibitory effect on hepatic cholesterol 
synthesis (Anderson \& Bridges, 1981). The present study did not address this question, but the low $\mathrm{pH}$ and the loss of viscosity in the caecal contents of the rats given oat gum confirms that this material is readily fermented by the caecal microflora.

We conclude that the soluble constituents of oats are a potentially important source of high-viscosity polysaccharides which have the capacity to modify the rheological properties of the gut contents. Such foods are relatively rare in Western diets, and oats may provide a more palatable source of viscous fibre than the legume products which are currently available. Further studies will be necessary to assess the effect of cooking and processing on the gastrointestinal effects of oats and products derived from them.

The authors acknowledge the technical assistance of Mr Gary Wortley.

\section{REFERENCES}

Anderson, J. W. \& Bridges, S. R. (1981). Plant fibre metabolites alter hepatic glucose and lipid metabolism. Diabetes 30, 133A.

Apling, E. C. \& Ellis, P. R. (1982). Guar bread: concept to application. Chemistry and Industry 950-954.

Blackburn, N. A. \& Johnson, I. T. (1981). The effect of guar gum on the viscosity of the gastrointestinal contents and on glucose uptake from the perfused jejunum in the rat. British Journal of Nutrition 46, $239-246$.

Blackburn, N. A. \& Johnson, I. T. (1983). The influence of guar gum on the movements of inulin, glucose and fluid in rat intestine during perfusion. Plügers Archiv 397, 144-148.

Blackburn, N. A., Redfern, J. S., Jarjis, H., Holgate, A. M., Hanning, I., Scarpello, J. H. B., Johnson, I. T. \& Read, N. W. (1984). The mechanism of action of guar gum in improving glucose tolerance in man. Clinical Science 66, 329--366.

Brown, N. J., Worldling, J., Rumsey, R. D. E. \& Read, N. W. (1988). The effect of guar gum on the distribution of the radiolabelled meal in the gastrointestinal tract. British Journal of Nutrition 59, 223-231.

Chow, S. L. \& Hollander, D. (1978). Initial cholesterol uptake by everted sacs of rat small intestine: kinetic and thermodynamic aspects. Lipids 13, 239-245.

De Groot, A. P., Luyken, R. \& Pikaar, N. A. (1963). Cholesterol-lowering effect of rolled oats. Lancet ii, 203-204.

Diamond, J. (1966). A rapid method for determining voltage concentration relations across membranes. Journal of Physiology 183, 83-100.

Duggleby, R. G. (1981). A non-linear regression programme for small computers. Analytical Biochemistry 110 , $9-18$.

Edwards, C. A., Johnson, I. T. \& Read, N. W. (1988). Do viscous polysaccharides slow absorption by inhibiting diffusion or convection? European Journal of Clinical Nutrition 42, 307-312.

Gee, J. M., Blackburn, N. A. \& Johnson, I. T. (1983). The influence of guar gum on intestinal cholesterol transport in the rat. British Journal of Nutrition 50, 215-224.

Gee, J. M. \& Johnson, I. T. (1985). Rates of starch hydrolysis and changes in viscosity in a range of common foods subjected to simulated digestion in vitro. Journal of the Science of Food and Agriculture 36, 614-620.

Gold, K. V. \& Davidson, D. M. (1988). Oat bran as a cholesterol-reducing dietary adjunct in a young, healthy population. Western Journal of Medicine 148, 299-302.

Heaton, K. W., Marcus, S. N., Emmett, P. M. \& Bolton, C. H. (1988). Particle size of wheat, maize, and oat test meals: effects on plasma glucose and insulin responses and on the rate of starch digestion in vitro. American Journal of Clinical Nutrition 47, 675-682.

Horn, N., Wyatt, G. M., Bayliss, C. E., Gee, J. M. \& Johnson, I. T. (1986). The effect of dietary fibres on bacterial densities in the rat intestine. Food Microbiology 3, 295-302.

Jenkins, D. J. A., Ghafari, H., Wolever, T. M. S., Taylor, R. H., Barker, H. M., Fielden, H. \& Bowling, A. C. (1982). Relationship between rate of digestion of foods and post-prandial glycaemia. Diabetologia 22, $450-455$.

Jenkins, D. J. A., Wolever, T. M. S., Leeds, A. R., Gassull, M. A., Haisman, P., Dilawari, J., Goff, D. V., Metz, G. L. \& Alberti, K. G. M. M. (1978). Dietary fibres, fibre analogues and glucose tolerance: importance of viscosity. British Medical Journal i, 1392-1394.

Johnson, I. T. \& Gee, J. M. (1981). Effect of gel-forming gums on the intestinal unstirred layer and sugar transport in vitro. Gut 22, 398-403.

Judd, P. A. \& Truswell, A. S. (1981). The effect of rolled oats on blood lipids and fecal steroid excretion in man. American Journal of Clinical Nutrition 34, 2061-2067.

Phillips, D. R. (1986). The effect of guar gum in solution on diffusion of cholesterol mixed micelles. Journal of the Science of Food and Agriculture 37, 548-552.

Pollay, M., Stevens, A. \& Kaplan, R. (1969). Diffusion of radioactive non-electrolytes in saline-agar gels. Analytical Biochemistry 27, 381-386. 
Rainbird, A. L., Low, A. G. \& Zebrowska, T. (1984). Effect of guar gum on glucose and water absorption from isolated loops in conscious growing pigs. British Journal of Nutrition 52, 489-498.

Simpson, H. C. R., Lousley, S., Geekie, M., Simpson, R. W., Carter, R. D., Hockaday, T. D. R. \& Mann, J. I. (1981). A high carbohydrate leguminous fibre diet improves all aspects of diabetic control. Lancet $\mathbf{i}, 1-5$.

Storch, K., Anderson, J. W. \& Young, V. R. (1984). Oat bran muffins lower serum cholesterol of healthy young people. Clinical Research 32, 740A.

Thomson, A. B. R. \& Dietschy, J. M. (1977). Derivation of the equations that describe the effects of unstirred water layers on the kinetic parameters of active transport processes in the intestine. Journal of Theoretical Biology 64, 277-294.

Trout, D. L., Ryan, R. O. \& Bickard, M. C. (1983). The amount and distribution of water, dry matter and sugars in the digestive tract of rats fed xanthan gum (41567). Proceedings of the Society for Experimental Biology and Medicine 172, 340-345.

Van Horn, L. V., Liu, K., Parker, D., Emidy, L., Liao, Y., Pan, W. H., Giumetti, D., Hewitt, J. \& Stamler J. (1986). Serum lipid response to oat product intake with a fat-modified diet. Journal of the American Dietetic Association 86, 759-764.

Wood, P. J. (1986). Oat $\beta$-glucan: structure, location, and properties. In Oats Chemistry and Technology, pp. 121-152 [F. H. Webster, editor]. St Paul, Minnesota: American Association of Cereal Chemists.

Wood, P. J., Siddiqui, I. R. \& Paton, D. (1978). Extraction of high-viscosity gums from oats. Cereal Chemistry 55, $1038-1049$. 